\title{
EI Queso y los Gusanos: un modelo de Historia critica para el analisis de las culturas subalternas
}

\author{
Carlos Antonio Aguirre Rojas \\ Instituto de Investigaciones Sociales \\ Universidad Nacional Autónoma de México
}

\section{RESUMO}

El presente ensayo intenta reconstruir las lineas principales del modelo de historia cultural que el microhistoriador italiano Carlo Ginzburg ha venido desarrollando desde hace ya casi cuatro decadas, y que se han plasmado de una manera ejemplar en su hoy ya celebre libro EL QUESO Y LOS GUSANOS. Asi, tratando de reconstruir tanto las versiones de historia cultural que este libro y este modelo ginzburguianos tratan de criticar y de superar, como tambien las filiaciones de los autores y perspectivas que este modelo pretende prolongar y asumir como antecedentes, el ensayo trata de dar cuenta de la singular originalidad especifica de esta propuesta de historia cultural de Carlo Ginzburg, caracterizada en parte por tratar de rescatar los problemas desde "la perspectiva misma de las victimas" de los procesos historicos estudiados.

Palabras clave: historia cultural crítica, microhistoria cultural, "perspectiva de las victimas".

\section{ABSTRACT}

This essay attempts to recreate the guidelines of the cultural history model that Carlo Ginzburg, the Italian micro historian, has been developing for almost four decades, and that was molded in a commendable way in his already famous book EL QUESO Y LOS GUSANOS. So, it tries to reconstruct the historical cultural versions that this book and the Ginzburg's model criticizes, as well other authors' perspectives for which this model intends to dwell and take on precedings over others. It deals with the unique originality of the specific cultural history proposal of Carlo Ginzburg, in part characterized by trying to draw on problems from "the victims own perspective" of the studied historical processes.

Keywords: cultural history, cultural micro history, "victim's perspectives". 
"A partir de un análisis preciso, la idea de una religión popular", ahistórica e inmóvil, se revela como insostenible. En su lugar hay que plantear la idea compleja de una lucha entre religión de las clases hegemónicas y religión de las clases subalternas, conformada como toda lucha, por confrontaciones abiertas, por compromisos, por situaciones de una paz forzada, por guerrillas".

Carlo Ginzburg, "Premessa Giustificativa" en Quaderni Storici, num. 41, 1979.

\section{La Universalidad y la Singularidad de El Queso y Los Gusanos}

¿Cuáles son los complejos factores que determinan el específico grado de difusión social de un libro o una obra cualquiera, y que implican que la misma sólo sea conocida, leída y discutida en escala local, o en otro caso en la dimensión nacional, pero también y a veces que sea traducida y difundida en escala continental o hasta a nivel planetario?. ¿Y cuáles son los elementos que inciden en el grado de su vigencia o permanencia a lo largo del tiempo, para hacerla un libro o una obra limitada a los tiempos de una moda, al impacto de pocos años, a la presencia durante las décadas de una sola coyuntura, o a la vigencia de periodos mas largos de todo un siglo o hasta pluriseculares en algunos casos?. ¿Y qué es lo que hace que sólo unos pocos y muy específicos trabajos o también autores se vuelvan verdaderos "clásicos" de referencia imprescindible dentro de las distintas áreas, campos, disciplinas o subdisciplinas de la cultura humana, mientras muchos otros de esos autores y trabajos no sobreviven al efecto del tiempo, que con los cambios constantes del conocimiento termina por superarlos y rebasarlos rápidamente?. ¿Y qué es lo que hace que mientras algunos de esos autores y libros son conocidos y debatidos universalmente, la inmensa mayoría en cambio no logra para nada o sólo muy escasamente trascender las barreras espaciales y lingüísticas que permanentemente acotan los límites de impacto de dichos autores y obras mencionadas?.

Sin intentar responder a estas complicadas interrogantes, lo que presupondría una reflexión particular amplia y compleja, si resulta interesante señalar que las mismas vienen a la mente, cuando intentamos explicarnos las razones de los vastos impactos y los prolongados efectos de obras importantes de la cultura y de las ciencias sociales contemporáneas. Y no hay duda de que entre estas últimas es posible incluir también al denso e interesante libro de Carlo Ginzburg titulado El queso y los gusanos. Un libro que, desde su primera edición, fue conquistando progresivamente un enorme éxito de difusión planetaria, a la vez que comenzaba a desplegar los profundos y diversos 
impactos intelectuales que, en una gran parte de las historiografías nacionales de todo el mundo, ha ido provocando a lo largo del último cuarto de siglo transcurrido ${ }^{1}$.

Porque después de su edición original en italiano, en 1976, el libro ha sido ya traducido a diecisiete diferentes lenguas, que incluyen desde el japonés, el albano o el serbo-croata hasta el neerlandés, el estonio y el sueco entre otros, al mismo tiempo que era abundantemente reeditado en italiano (quince reimpresiones hasta el año de 1997), para alcanzar una cifra global de copias editadas en todas estas lenguas, sin duda superior a los 70,000 ejemplares publicados. Así, convirtiéndose en uno de los libros obligados dentro de la formación de cualquier estudiante serio de historia en la actualidad, y también en el libro de Carlo Ginzburg más conocido y difundido dentro del conjunto de toda su producción intelectual ${ }^{2}$ El queso y los gusanos ha rebasado incluso el círculo específico de los historiadores, para ser también leído, comentado y utilizado por parte de lingüistas y literatos, lo mismo que de filósofos, epistemólogos y especialistas diversos de los temas culturales.

¿A qué se debe entonces esa vasta difusión de este libro y las múltiples traducciones que ha suscitado?. ¿Y por qué ese éxito enorme entre historiadores, científicos sociales y especialistas de las humanidades de prácticamente todos los rincones del mundo?. En nuestra opinión, esa difusión y éxito excepcionales se deben, en primer lugar, al contexto que, en el mundo entero, fue construido como resultado de la profunda revolución cultural mundial de 1968, contexto que creó un medio particularmente receptivo y atento para todas aquellas perspectivas, corrientes, obras y enfoques que, desde muy distintos ángulos, comenzaron a ocuparse justamente del examen e interpretación de los distintos fenómenos, problemas, temas y procesos que constituyen a esa compleja dimensión que es la cultura de las sociedades humanas, actuales y antiguas.

Y en segundo lugar, al hecho de que en esta obra de El queso y los gusanos se encuentra contenida la propuesta de un nuevo modelo de historia crítica para el examen de las culturas subalternas, modelo que al mismo tiempo que ajustaba cuentas con las principales formas anteriores de abordar este complicado universo de la cultura de las clases populares, e incluso con algunas otras propuestas para la historia cultural que le han sido contemporáneas, postulaba una versión de historia cultural que se destacaba de todas esas otras versiones contemporáneas por una mayor y singular elaboración, originalidad $y$ universalidad específicas. Y es a la vez este deslinde explícito frente a otros posibles modelos de la historia de la cultura, junto a esta mayor universalidad, singularidad y sofisticación, las que explican también, en nuestra opi- 
nión, esa amplia difusión planetaria y esos profundos impactos intelectuales de ese libro de Carlo Ginzburg publicado en $1976^{3}$.

Revisemos entonces, con más detalle, tanto este contexto post- 68 como los elementos de dicho nuevo modelo de historia cultural, que va a construirse críticamente lo mismo frente a los modelos anteriores que frente a los modelos que le son contemporáneos, en esta línea de intentar explicar en positivo, ese importante tema de la historia de las culturas de las clases ubicadas en la condición de sometimiento y subalternidad por las clases hegemónicas de la sociedad.

\title{
Los Diversos Contextos Posteriores a
}

\section{La Revolución Cultural Mundial de 1968}

\author{
“También en este campo el 68 representó, como es \\ obvio, un cambio de dirección". \\ Carlo Ginzburg, "Introduzione” a la edición \\ italiana del libro de Peter Burke, \\ Cultura popolare dell'Europa Moderna, 1980.
}

Cuando el libro de Carlo Ginzburg titulado El queso y los gusanos. La cosmovisión de un molinero en el siglo XVI es publicado en Italia, en 1976, toda la historiografía occidental se encuentra viviendo los efectos inmediatos de la amplia serie de revoluciones culturales que, entre 1966 y 1969, sacudieron de maneras diversas a prácticamente todas las naciones del planeta. Porque desde China hasta Estados Unidos, lo mismo que desde Argentina o la India hasta Checoslovaquia o Canadá, la revolución mundial de 1968 puso en cuestión y terminó transformando de raíz a todo el conjunto de las estructuras culturales de las sociedades modernas de todo el planeta.

Con lo cual y de manera evidente, el tema de la cultura en sus múltiples expresiones y manifestaciones de todo tipo, pasó a convertirse en uno de los temas centrales del debate contemporáneo en todas las ciencias sociales de las últimas tres décadas recién vividas. E igual que en la sociología, la antropología, la psicología o la ciencia política entre otras, también en la historia comenzó a ganar terreno y centralidad, después de 1968, esa rama de la historia cultural, que si bien había existido y había sido cultivada desde mucho antes, no había en cambio florecido de una manera tan plural, múltiple y ubicua como lo hará en esas condiciones posteriores a la revolución de 1968.

No es entonces por simple azar, que a partir de los años setentas del siglo cronológico pasado, veamos afirmarse y prosperar todos esos distintos 
proyectos intelectuales, que constituyen otros tantos intentos de aproximación a este mismo campo de la moderna historia cultural, y que son la historia de las mentalidades francesa o la psicohistoria inglesa y norteamericana, parte de los trabajos de la más general antropología histórica rusa o ciertas vertientes de la nueva historia social alemana, junto a ciertas líneas dentro de la historia marxista británica o a la llamada historia intelectual norteamericana, entre otras.

Diversas corrientes o autores dentro del vasto paisaje de los estudios históricos post-68, que al abocarse al estudio de los distintos renglones de la historia cultural, dan una de las varias respuestas intelectuales posibles, a la lógica necesidad que todas las sociedades del planeta experimentan, después de 1968 , de un examen y un esclarecimiento mayores de esa misma cultura, entonces inmersa en un profundo proceso de total transformación.

Y es justo dentro de este contexto global, de especial receptividad y hasta de reclamo de distintas explicaciones para estos fenómenos culturales, que aparece en Italia el libro de El queso y los gusanos, libro cuya intención manifiesta y cuya hipótesis articuladora central es justamente la de entregarnos las claves para el desciframiento esencial de los códigos principales que constituyen el esqueleto específico de la cultura campesina italiana y europea durante el 'largo siglo XVI'. Aunque también, y a través del examen minucioso de la singular cosmovisión del molinero Menocchio, lo que en realidad Carlo Ginzburg intenta descifrar es ese código de comprensión que nos dé el acceso a las principales estructuras profundas, primero de una de las mas importantes culturas subalternas presentes en esa Italia y esa Europa del siglo XVI, de la cultura específicamente campesina, pero también y en segundo lugar, de varios de los elementos fundamentales de la mas general cultura de las clases populares italianas y europeas, estructuras que si bien van a manifestarse de una manera más perceptible y evidente durante ese singular nudo histórico privilegiado que es el 'largo siglo XVI', inscriben en cambio su vigencia y su funcionamiento más esencial en los propios registros de la larga duración histórica, explicitada alguna vez por Fernand Braudel ${ }^{4}$.

Con lo cual, El queso y los gusanos va a constituirse, desde su propia aparición, en la particular contribución italiana a ese mismo movimiento general de la historiografía occidental, que en aquellos lustros aborda desde diversos ángulos y enfoques, y en muchos países y simultáneamente, a este campo ya referido de la historia cultural. Contribución italiana a la historia cultural europea y occidental entonces en auge, que se empata además con la emergencia misma de la más importante corriente historiográfica italiana desar- 
rollada en todo el siglo XX, y que es la hoy célebre corriente de la microhistoria italiana ${ }^{5}$.

Ya que es justamente en esos años setentas cuando va a ir conformándose, en torno de la revista Quaderni Storici, el pequeño pero activo e innovador grupo que será el "núcleo duro" del proyecto intelectual de esa microhistoria italiana, y cuyos representantes principales han sido hasta hoy Eduardo Grendi, Giovanni Levi, Carlo Poni y el mismo Carlo Ginzburg. Un pequeño grupo de historiadores críticos, de izquierda y profundamente inconformes con las viejas y tradicionales formas de hacer historia entonces imperantes en Italia, que en 1976 van a encontrar en El queso y los gusanos, no sólo un logrado ejemplo del procedimiento microhistórico que entonces ellos están en vías de teorizar y explicitar ${ }^{6}$, sino también una obra que inaugura, dentro de ese mismo proyecto global microhistórico, el área de la entonces debatida y omnipresente historia cultural.

Lo que va a establecer un mecanismo de doble retroalimentación entre esa obra de Ginzburg y dicha corriente de la microhistoria italiana. Pues si la propia afirmación y proyección internacional de esa microhistoria italiana, va a coadyuvar también a la difusión mayor y al impacto creciente de El queso y los gusanos, es porque en este último libro dicha microhistoria va a encontrar uno de los primeros resultados de investigación que ella puede mostrar como ejemplo y como emblema de lo que justamente persigue y defiende en tanto que nuevo proyecto historiográfico específicamente microhistórico.

Apoyando entonces ella misma de una manera fundamental, y apoyándose a su vez en esta difusión primero italiana, luego europea y finalmente mundial que en el último cuarto de siglo irá ganando esta corriente de la microhistoria italiana, la que a su vez lo ha convertido en uno de sus libros emblemáticos y paradigmáticos centrales, El queso y los gusanos comenzará a correr fortuna dentro del mundo, al mismo tiempo como dicha obra emblemática, entre otras, de este proyecto intelectual de la microhistoria italiana, pero también como una de las mas importantes piezas de la peculiar contribución de Italia a este campo en fuerte crecimiento y expansión mundial, que es el de los estudios históricos de la dimensión cultural del mundo humano social.

Pero, si dentro de este doble contexto propicio, italiano y mundial, para su proyección internacional, el libro de El queso y los gusanos ha podido jugar tal papel y tener tales ecos intelectuales, ello se debe también, en una medida esencial, al hecho de que dentro de sus páginas se encierra, tanto una crítica y un intento de superación de otros varios modelos alternativos para el desarrollo de la historia cultural, como también la propuesta en positivo de una forma novedosa, sutil y muy universal para el estudio y el análisis de estos mismos fenómenos culturales enfocados desde una perspectiva densamente histórica. 
El Queso y los Gusanos: un modelo de Historia critica para el analisis de las culturas subalternas

\title{
La Crítica de Algunos Modelos de EXPliCACión DE LA Historia CUlTural
}

\author{
“La 'mentalidad' (que por lo demás es un término mediocre \\ que se presta a ciertos equívocos, como lo testimonia la \\ oposición que usted ve de este término y que yo no veía, \\ con la noción de 'sensibilidad'...”.
}

Marc Bloch, Carta a Lucien Febvre, 8 de mayo de 1942.

Sin duda, el modelo alternativo de historia cultural más difundido contemporáneamente a la escritura y primera difusión de El queso y los gusanos, ha sido el célebre modelo de la historia francesa de las mentalidades. Una historia de las mentalidades que, gracias al rol hegemónico que la historiografía francesa detentó en el mundo occidental, entre 1945 y 1968 aproximadamente, pudo proyectarse ampliamente en toda Europa y en el mundo, llegando a provocar la creación de neologismos en las lenguas inglesa y alemana — los términos antes inexistentes de mentalities y mentalitët respectivamente-, y dando lugar a la creación de seminarios o proyectos o ejercicios de historia de las mentalidades lo mismo en México, Brasil o Estados Unidos, que en España, Rusia, Turquía o la India entre otros países.

Así, difundiendo una amorfa y nunca bien definida historia de las "mentalidades", que en algunos de sus propios representantes principales se autodeclaraba como una historia "ambigua", los historiadores franceses proyectaron en todo el mundo este modelo de historia cultural que, más allá de su enorme éxito y de su rápida difusión internacional — debida en gran parte al brillo y a la influencia que había conquistado la corriente de los Annales entre 1929 y 1968 en el planeta entero-, comenzó a ser objeto de fuertes y sólidas críticas ya desde esos mismos años setentas que fueron también los de su primer gran auge y amplia afirmación ${ }^{7}$.

Historia francesa de las mentalidades, al mismo tiempo muy difundida y muy criticada, que también será cuestionada centralmente en el Prefacio de El queso y los gusanos, señalando tanto su omisión inaceptable, presente en la versión de Jacques Le Goff, de la división de las sociedades en clases sociales y su ignorancia de las implicaciones fundamentales que tiene esta división en el ámbito cultural, como también su incapacidad de distinguir, en el caso de la historia de las mentalidades construida por Robert Mandrou, entre la cultura impuesta a las clases populares por las clases dominantes, y la cultura generada directamente por esas mismas clases subalternas, como fruto de su propia actividad y experiencia sociales.

Deslindándose entonces de esta limitada historia cultural de las mentalidades, que ignora el conflicto social también presente y también determinan- 
te dentro de la esfera cultural, Carlo Ginzburg se distancia de ese mismo modelo de historia cultural que hace imposible captar, en sus diferencias y en sus especificidades, a esas culturas de las clases subalternas que son el objeto privilegiado de atención de este mismo autor de El queso y los gusanos. Y vale la pena insistir en el hecho de que, si esa historia de las mentalidades estará en boga en todo el mundo en los años setentas y en el primer lustro de los años ochentas, terminará en cambio por entrar en crisis en el segundo lustro de esos años ochentas, para ser ya totalmente abandonada por parte de todos los historiadores serios y científicos de Francia, de Europa y de todo el planeta en el curso de los años noventas recién vividos.

Historia de las mentalidades francesa que, si bien cumplió en su momento la doble función positiva de, en primer lugar, denunciar las limitaciones de la más tradicional y elitista historia de las ideas, que había sido dominante en gran parte de la historiografía europea anterior a 1968, y en segundo lugar la de animar y popularizar un poco en todas partes ese estudio de los diversos renglones de la moderna historia cultural, demostró también y muy rápidamente sus propios límites conceptuales, metodológicos y teóricos, para ser capaz de abordar en toda la complejidad requerida, a esta misma agenda diversa del vasto universo que implica el adecuado tratamiento crítico e innovador de una compleja y densa historia de los procesos culturales, del pasado y del presente de las distintas sociedades humanas.

Por eso, no es casual que junto a las críticas dirigidas a esta historia gala de las mentalidades, aparezca también en ese Prefacio de El queso y los gusanos, como un segundo blanco a criticar y superar, esa recién mencionada historia tradicional de las ideas, que teniendo en Italia una presencia e influencia particularmente relevantes, ha reproducido el punto de vista aristocrático y despreciativo que ni siquiera reconoce la existencia misma de la cultura popular, calificando en cambio a los fenómenos culturales y a las concepciones y cosmovisiones de las clases subalternas, solamente como "folklor", como "artes y tradiciones populares", como "creencias y visiones primitivas del mundo", pero no como verdadera y estricta "cultura".

Así, identificando el concepto de cultura exclusivamente con la cultura de las clases hegemónicas, esta historia de las ideas presente en la historia de la literatura, en la historia de las ciencias y en la historia del pensamiento y de las doctrinas ampliamente cultivada hasta antes de 1968, va a irse viendo progresivamente cuestionada tanto por los desarrollos de la antropología y de la etnología críticas del siglo XX, como también por las distintas corrientes innovadoras de la historiografía de los dos primeros tercios del siglo XX cronológico, para terminar deslegitimándose completamente bajo los impactos de la revolución cultural de 1968.

Una historia aristocrática y tradicional de las ideas, que al asumir la falsa 
concepción de que sólo las clases dominantes pueden "producir" y generar cultura, niega de plano la posibilidad de hablar de una cultura popular, o en otra vertiente, fruto ya de esos cuestionamientos de la historiografía y la antropología críticas contemporáneas, construye el modelo de la cultura como un fenómeno unilateral y siempre "descendente", que será producido permanentemente por las elites para luego ser "imitado", aprendido, asimilado y reproducido, de manera pasiva y siempre más tardía y más imperfecta, por las propias clases populares. Con lo cual, la cultura popular no sería nunca más que una suerte de "reflejo retardado o posterior" de la cultura de elite, la que a su vez sería la única cultura nueva y originaria, generada y producida constantemente solo por esas mismas clases dominantes, las que al poseer el tiempo, las condiciones materiales y el reposo necesario para la "creación" cultural serían las únicas detentoras del monopolio de la producción cultural en general ${ }^{8}$.

Visiones 'aristocrática' y 'descendente' de la cultura y de la cultura popular, que Carlo Ginzburg criticará también frontalmente, demostrando como la generación de la cultura no es para nada privilegio de las clases dominantes, existiendo por el contrario una cultura popular generada, reproducida y renovada constantemente por las mismas clases subalternas, dentro de una relación de permanente circularidad cultural, en la que las clases hegemónicas se "roban" los temas, productos y motivos de esa cultura subalterna, para transformarlos y utilizarlos como armas de su legitimación social y cultural, y en la que, igualmente, las clases sometidas sólo se "aculturan" parcial y mudablemente, resistiendo a la imposición de la cultura hegemónica, salvaguardando elementos de su propia cultura, y refuncionalizando a veces el sentido y la significación de esa misma ideología y cultura dominante y hegemónica que les es impuesta.

Otra de las posiciones en torno de la historia cultural criticadas por Ginzburg, será la postura de Michel Foucault y de sus seguidores, que reconociendo la existencia e importancia de la cultura popular, insisten en cambio en su inaccesibilidad total. Pues dado que durante siglos y milenios la inmensa mayoría de las clases populares no saben leer ni escribir, entonces su cultura sólo nos llega a través del testimonio de las propias clases dominantes, y por lo tanto deformado y sesgado hasta tal punto que se vuelve en el fondo indescifrable.

Frente a esta postura, Ginzburg reconocerá la dificultad enorme que implica la reconstrucción de esa cultura de las clases subalternas, pero no para aceptar que es simplemente inaccesible, sino más bien para buscar los modos oblicuos, las formas de interpretación a contrapelo, las estrategias de lectura intensiva e involuntaria, y los modos de aplicación del "paradigma indiciario", necesarios para el complejo acceso hacia esas culturas subalternas y hacia el desciframiento de sus códigos y estructuras principales.

Finalmente, Carlo Ginzburg va también a señalar los límites de las dis- 
tintas variantes de la historia cuantitativa y serial de los fenómenos culturales, historia que al privilegiar los fenómenos "de masa", cuantificables y serializables, tiende a olvidar o a marginar la relevancia de los aspectos más cualitativos, ignorando, por ejemplo en la historia serial y cuantitativa del libro, cómo es que esos libros eran leídos y asimilados por sus distintos lectores, y cómo entonces detrás de las cifras duras del número de lectores se oculta y se olvida el fundamental problema de las heterogéneas y diversas formas de la recepción cultural, tan brillante y extraordinariamente ejemplificadas, justamente, en el caso del molinero Menocchio. O también, y en virtud de la inevitable "normalización" de los casos individuales que conlleva esa historia cuantitativa de la cultura, es que resulta imposible analizar a esos casos atípicos pero profundamente reveladores de dichas culturas subalternas, que son por ejemplo el grupo de los Benandanti, o también el del molinero Menocchio, casos que, por el contrario, son uno de los objetos de estudio privilegiados y elegidos desde esta perspectiva microhistórica específica, que ha sido también trabajada y explicitada por el propio Carlo Ginzburg.

Alejándose entonces de la simple y tradicional histoire événementielle, este modelo de historia cultural puesto en acto en El queso y los gusanos es sin embargo capaz de rescatar este estudio microhistórico de dichos casos excepcionales, que por su misma atipicidad resultan especialmente reveladores de las estructuras generales y de los contenidos principales de esa cultura popular o subalterna, que Ginzburg intenta aprender y caracterizar de manera global ${ }^{10}$.

Deslindándose entonces de estas distintas variantes de la historia cultural, El queso y los gusanos va igualmente a reivindicar la herencia de otras aproximaciones a este mismo campo de los estudios históricos culturales, reconociendo sus diversas filiaciones y entronques diferentes con los aportes de Marc Bloch y de Mijail Bajtin, pero también y en otro sentido de Edward P. Thompson y Natalie Zemon Davis.

\section{Las Herencias y Filiaciones Reconocidas de El Queso y Los Gusanos}

"No era cosa de estudiar los ritos de curación aisladamente,... (y) sin vinculación alguna con las tendencias generales de la conciencia colectiva".

Marc Bloch, Los reyes taumaturgos, 1924.

En diversas ocasiones y entrevistas, Carlo Ginzburg ha reconocido la importancia fundamental que para su elección de la profesión de historiador y para su propia formación ha tenido la obra de Marc Bloch en general, y muy en particular el bello libro de Los reyes taumaturgos ${ }^{11}$. Lo que también se refle- 
ja de manera clara en el modelo de historia cultural que Carlo Ginzburg va a poner en acción en el libro de El queso y los gusanos. Porque de la misma manera en que Bloch ha construido un complejo modelo estratificado, que para explicar la creencia popular en el poder taumatúrgico de los reyes franceses e ingleses, va a descomponer y a recomponer los distintos estratos que conforman a la conciencia colectiva popular de la Francia y la Inglaterra de los siglos XIII a XVIII, así también Ginzburg va a intentar desarticular y rearticular todos los diversos niveles componentes de esa cultura campesina de la Italia del siglo XVI subyacente a la cosmovisión del molinero Domenico Scandella.

Lo que, evidentemente, lleva tanto a Bloch como a Ginzburg por los senderos de la discriminación de las diversas temporalidades históricas que corresponden a esos diferentes estratos culturales que van a condensarse, en un caso, en la creencia taumatúrgica del milagro de la realeza francesa e inglesa, y en el otro, en la singular cosmovisión del molinero Menocchio, quemado finalmente por la inquisición. Y es de este modo, que Bloch va reconstruyendo y superponiendo, desde la proyección que va a darse a nivel cultural de los efectos de los distintos ciclos coyunturales de la mayor o menor popularidad de los reyes o de su mayor o menor iniciativa de afirmación dentro de Europa, y pasando por el conflicto secular en torno a los respectivos ámbitos de poder entre la iglesia y el Estado durante el periodo del fin de la Edad Media y del tránsito hacia la modernidad, hasta las vicisitudes de la más ampliamente difundida creencia en la naturaleza "sagrada" de los reyes y de sus linajes, y por ende de su capacidad de hacer milagros, y también, finalmente, de las características de la conciencia colectiva popular en la larga época precapitalista, que todavía hasta los siglos XVI-XVIII continuaba aceptando y percibiendo como algo lógico la vigencia de lo "sobrenatural" dentro del mundo.

Por su parte, e imitando en este sentido esa reconstrucción blochiana de la cultura de las clases subalternas, concebida como esta sintesis compleja de diversos estratos culturales, que nos remiten a las distintas duraciones históricas de las varias dimensiones que se condensan y confluyen siempre en cualquier manifestación cultural relevante, Carlo Ginzburg va también a correr hacia atrás el hilo de la historia, para irnos reconstruyendo igualmente los varios posibles estratos presentes en la cosmovisión de Domenico Scandella, que abarcan desde un vago "luteranismo" y a la atmósfera creada en Italia y en Europa por las polémicas ilustradas del movimiento de la reforma religiosa, hasta concepciones profundas y milenarias constitutivas de la cultura popular campesina europea, y pasando por varios estratos intermedios que incluyen lo mismo el panteísmo, la tolerancia religiosa y el materialismo espontáneos de la cultura de las clases subalternas, junto a los siempre parcialmente fallidos aunque reiterados intentos de cristianización completa de 
las clases populares, que las utopías tenaces de esas clases sometidas en torno al 'País de Cucaña', entre otros varios.

Anticipando entonces, de manera práctica Marc Bloch, y ejemplificando brillantemente Carlo Ginzburg, la teorización de Fernand Braudel sobre las diferentes temporalidades y duraciones históricas, tanto Bloch como Ginzburg van a enseñarnos que la cultura popular o de las clases subalternas no es nunca un espacio homogéneo, y además limitado a ser el "reflejo" intelectual de una cierta "situación material" igualmente homogénea y limitada temporalmente, sino por el contrario, una suerte de palimpsesto múltiple, conformado por elementos culturales de muy heterogéneas duraciones y vigencias históricas, y articulado siempre de maneras complejas, que además están dentro de un proceso de constante refuncionalización y transformación sistemáticas.

Un segundo antecedente fundamental reivindicado por Carlo Ginzburg, lo constituye la obra de Mijail Bajtin, La cultura popular en la Edad Media y en el Renacimiento. El contexto de Francois Rabelais ${ }^{12}$, una obra en la que además de mostrarse la fuerza y el vigor intrínsecos de la cultura popular, y su inagotable capacidad de generar autónomamente y de modo permanente nuevas formaciones, visiones y contenidos culturales, se intenta también descifrar algunos de los códigos de su funcionamiento en general, y también algunas de sus características distintivas esenciales.

Con lo cual, no sólo se elimina totalmente a la visión "aristocrática", que niega la existencia de esta cultura popular, y también a la visión "descendente" que la concibe como mero reflejo pasivo y tardío de la cultura hegemóni$\mathrm{ca}$, sino que se reivindica claramente el papel activo que las clases subalternas tienen como, incluso, los principales agentes de la creación cultural en general, además de entregarnos varias claves esenciales para la comprensión de esta cultura popular, aquí concebida como una cultura diversa y opuesta a la cultura oficial, pero también como una cultura profundamente creativa, innovadora y fluida.

Cultura popular que se manifiesta de manera privilegiada en la plaza pública, en el carnaval y en la fiesta, y que es hasta cierto punto "dialéctica" de un modo espontáneo y natural, al mismo tiempo que es totalizadora, dinámica y abierta al cambio y a la transformación, a partir de sus formas jocosas, festivas y risueñas, y de sus contenidos muchas veces antiautoritarios, antijerárquicos, desacralizadores, ambivalentes y niveladores, lo mismo que actualizados constantemente por el mecanismo de "poner al mundo al revés" tan característico de esta misma cultura popular ${ }^{13}$.

Una cultura popular que es todo un complejo universo, todavía por descifrar y analizar más profundamente, y que habiendo mantenido durante toda la larguísima etapa precapitalista una relación de mayor fluidez e intercambio con la cultura hegemónica, va a "invadir" una gran parte de la esfera 
global de la cultura europea del siglo XVI, justamente en ese momento de transición histórica privilegiada que ha sido dicho "largo siglo XVI", en el que la cultura hegemónica medieval se encuentra ya en una crisis total y en proceso de retirada, mientras que la nueva cultura burguesa característica de la modernidad capitalista no ha terminado aún ni de conformarse, ni de afirmarse socialmente de manera integral ${ }^{14}$. Lo que, según Bajtin, es la clave para explicar una obra literaria tan singular como la de Francois Rabelais.

Asimilando entonces todas estas lecciones y pistas abiertas de investigación señaladas por Bajtin, Carlo Ginzburg va a tratar de ir un poco más allá de ellas y de su propia formulación bajtiniana, planteándose a sí mismo el objetivo de acceder a esos estratos profundos de la cultura popular, pero no para verlos a través de la visión de las clases hegemónicas, o como Bajtin, a través de las versiones del propio Francois Rabelais, sino desde el punto de vista de las propias clases subalternas, desde el "punto de vista de las victimas" como dirá más adelante el mismo Ginzburg. Por eso nuestro autor va también a tratar de encontrar, por debajo y más allá de las influencias de las culturas reformistas, heréticas, o racionalistas presentes en el siglo XVI, esa específica estructura de la cultura popular subyacente y determinante de la cosmovisión de Menocchio, que si bien puede igualmente recuperar a los mencionados elementos de lo que es claramente una crítica interna de esa misma cultura de elite o hegemónica, lo hace siempre desde sus propios códigos autónomos y desde sus propias estructuras específicas.

Finalmente, un tercer antecedente reivindicado por Ginzburg, es el de algunos ensayos y libros publicados por Edward P. Thompson y Natalie Zemon Davis $^{15}$ que nos demuestran que, aunque difícil de acceder a ella y aunque siempre sesgada por las grandes lagunas, insuficiencias y dispersión de la documentación, no es sin embargo imposible lograr la reconstrucción y el examen de esa cultura de las clases subalternas, la que aunque sea de manera oblicua, fragmentaria, indiciaria, en negativo, o marginal, alcanza a manifestarse y a aparecer a la mirada del historiador realmente acucioso e inteligente.

Porque, como lo ha mostrado brillantemente E. P. Thompson, esta cultura popular implica entre muchas otras cosas, también la existencia de un barómetro o lógica general que, más allá de lo que digan las leyes, determina lo que en el sentimiento popular y en la cultura de esas clases oprimidas es tolerable y lo que es inaceptable, lo que es moralmente legítimo y aceptado por todos, frente a aquello que resulta intolerable, agresivo para las costumbres de la comunidad, y por ende incluso moralmente condenable. Es decir, la existencia de una verdadera "economía moral de la multitud", que siendo parte de esos códigos y de esa lógica de funcionamiento de la cultura de las clases subalternas, es la que determina el momento en que, desde un malestar latente o desde una situación de contraposición habitual pero aparentemente tranqui- 
la, se pasa de pronto hacia un motín, una huelga, una rebelión abierta, o incluso una insurrección general y hasta una revolución social completa.

Recuperando entonces de estos trabajos mencionados de Thompson y Zemon Davis, ciertos "aspectos particulares" y a veces decisivos de dicha cultura de las clases subalternas, Carlo Ginzburg completa y apuntala los antecedentes principales a partir de los cuales construirá el modelo de historia crítica para el análisis de las culturas subalternas, que se ha plasmado de manera tan brillante en su obra sobre El queso y los gusanos.

\title{
Algunas Piezas Del “Rompecabezas” para
}

\section{El desciframento de La Cultura de Las Clases Subalternas}

\begin{abstract}
"Como todos saben, la vida intelectual en Italia estuvo impregnada por el marxismo. Mi encuentro con Gramsci fue sin duda algo muy importante (...) Leí a Hegel y a Marx en el Curso de un intelectual comunista llamado Cesare Luporini, que era una figura interesante. Y evidentemente, eso también me marcó...”.

Carlo Ginzburg, "História e Cultura: Conversa com Carlo Ginzburg”, 1990.
\end{abstract}

Con el libro de El queso y los gusanos, alcanza una primera maduración importante el modelo de historia cultural que Carlo Ginzburg había comenzado a edificar desde su libro I benandanti, publicado en 1966, y que sin duda continuará afinando y enriqueciendo en distintos aspectos después de 1976, primero extrayendo una buena parte de las lecciones metodológicas principales que se derivan de su itinerario y de sus diversas investigaciones, en su célebre ensayo de 1979 titulado "Espías. Raíces de un paradigma indiciario", y después en toda una serie de ensayos que culminarán con la publicación de su libro Historia nocturna en $1989^{16}$. Primera maduración que implica ya toda una concepción sistemática sobre un posible modo de abordar históricamente este complejo tema de la cultura de las clases subalternas, cuyos rasgos principales vale la pena considerar aquí de manera más detenida.

La primera idea importante que subyace a este modelo de historia cultural es la tesis de que dicha historia de la cultura es un campo absolutamente reciente y muy joven dentro de los estudios históricos en general, y por lo tanto un verdadero campo todavía en construcción, en lo que se refiere a la definición de sus diversas zonas problemáticas y de los distintos renglones que abarca, pero también en cuanto a la elaboración más fina y puntual de sus 
principales conceptos, de sus paradigmas metodológicos, de sus modelos explicativos y de sus hipótesis articuladoras principales ${ }^{17}$.

Porque como bien lo ha señalado Ginzburg, la cultura de las clases subalternas no podía convertirse en un objeto de estudio antes de que la disciplina histórica se abriera al vasto campo de su dimensión como historia social, como historia de las clases, de las masas y de los grandes grupos colectivos de la sociedad, lo que como es bien sabido, no acontecerá más que a partir de la segunda mitad del siglo XIX, y de la revolución que ha implicado el marxismo para la propia evolución de dicha ciencia histórica ${ }^{18}$.

Y todavía después de este nacimiento señalado de la historia social, la afirmación de dicha historia de la cultura popular no se desarrollará más que muy lenta y progresivamente, gracias a los desarrollos de la antropología y de la historiografía críticas del siglo XX, y del concomitante abandono de aquella postura aristocrática, tradicional y anacrónica, que aún después del surgimiento del marxismo, continuó todavía por décadas relegando a dicha cultura popular al simple estatuto de "folklor", "demología" o "artes y tradiciones populares", como ya hemos señalado antes.

Junto a este carácter muy joven de la historia cultural, está la clara tesis de que dicha cultura no es algo ni unitario ni homogéneo, sino más bien un campo de fuerzas dividido y contradictorio, que se encuentra siempre conformado por dos universos diferentes, el de la cultura hegemónica (y no sólo "dominante") y el de las múltiples culturas subalternas (y no sólo la cultura "popular"). Porque siguiendo en este punto las importantes y decisivas lecciones de Antonio Gramsci, Ginzburg va a concebir a la cultura de las clases dominantes como cultura "hegemónica", es decir como una cultura que no sólo ejerce el dominio, por la vía de la imposición o el avasallamiento total, sino también por la vía de la creación de un cierto "consenso" cultural, que a la vez que la obliga a "apoderarse" de ciertos temas, motivos y elementos de la cultura popular, para deformarlos y usarlos como arma de su propia legitimación, la impulsa también a promover permanentemente distintos esfuerzos de "aculturación" de esas clases subalternas, encaminados obviamente a arraigar y a hacer aceptable dicha cultura hegemónica por parte de esas mismas clases sometidas.

Igualmente, y tratando de superar tanto una visión "transclasista" de la cultura (implícita en el concepto de "mentalidad") como una visión "clasista genérica" de la misma (subyacente al término de cultura "popular", es decir la cultura del amorfo e indefinido, pero también inexistente "pueblo"), Carlo Ginzburg va a postular más bien la noción de "culturas subalternas", es decir de múltiples culturas correspondientes a las diferentes clases y a los diferentes grupos sociales sometidos, que si bien se encuentran en dicha situación de "subalternidad" y de sometimiento, no por ello dejan de afirmar su propia 
cultura, diferente de la cultura hegemónica, aunque se encuentre sometida y subsumida por ella, pero que sin embargo y en virtud de esta condición de cultura subalterna, mantiene su propia lógica específica y sus singulares expresiones sólo típicas de ella misma, alimentando a la vez la resistencia cultural de los oprimidos, y la necesaria renovación permanente de las iniciativas culturales hegemónicas de las clases dominantes ya referidas.

Concepción que distingue claramente a dicha cultura hegemónica de las culturas subalternas, que lleva a Carlo Ginzburg a la afirmación de una doble tesis, sólo en apariencia paradójica: para el autor de El queso y los gusanos, el espacio de la cultura es a un mismo tiempo un campo de batalla permanente, donde se enfrentan sin cesar cultura hegemónica y cultura subalternas, pero también y simultáneamente, un terreno marcado idénticamente por un movimiento de circularidad constante, en donde ambas versiones culturales intercambian todo el tiempo elementos, cosmovisiones, motivos y configuraciones culturales, como parte de esa misma batalla cultural que los interconecta y sobredetermina en general.

Porque superando radicalmente la idílica pero falsa visión de una "mentalidad" que sería común a Julio César y al más humilde de sus soldados, o a Cristóbal Colón y al último de sus marineros, Ginzburg va en cambio a enfatizar el hecho de que el conflicto social global que caracteriza y que ha caracterizado a la inmensa mayoría de las sociedades humanas dentro de la historia, se reproduce también dentro de la esfera cultural, contraponiendo sistemáticamente a la cultura de las clases dominantes con la cultura de las clases populares, dentro de un esquema asimétrico en el que, como es obvio, los "dados están siempre cargados" en beneficio de los dominadores y de las elites en el poder.

Pero al mismo tiempo, y justamente para hacer posible esta construcción de una hegemonía cultural por parte de las clases privilegiadas de una sociedad, es que se desarrolla esa circularidad cultural permanente, que determina que sólo logran arraigar y afirmarse socialmente aquellos mensajes, códigos y visiones de la clase dominante que, de una manera u otra, consiguen conectarse y refuncionalizar en sentido legitimador de dicha dominación, a los temas, problemas, concepciones del mundo o elementos culturales previamente existentes, y ya antes difundidos y enraizados en esas mismas culturas de las clases populares. Lo que explica, por mencionar sólo algunos ejemplos posibles, el hecho de que el calendario cristiano en Europa se haya reapropiado, copiándolas, de las fechas de las fiestas paganas precristianas, pero también el hecho de que los primeros santuarios de la Virgen de Guadalupe en la Nueva España, se ubicaran muchas veces, sospechosamente, en los mismos lugares de culto de las antiguas diosas de la fertilidad de las diversas culturas prehispánicas. 
Pero también, y en el otro extremo, resulta claro que las clases subalternas no aceptan nunca de manera pasiva y tranquila esa imposición cultural hegemónica de las clases dominantes, sino que la someten persistentemente, a una recodificación que, más allá de su vocación legitimadora del statu quo, vuelve a filtrar las actitudes de resistencia y hasta de abierta rebeldía cultural, apropiándose lo mismo de ciertos elementos de dicha cultura hegemónica para utilizarlos en sus propias luchas cotidianas, que recreando y generando constantemente nuevas figuras y elementos de cultura, aún no filtrados por el código hegemónico, y que permanecen por algún tiempo como expresiones genuinas de esa inagotable y siempre renovada cultura subalterna de múltiples rostros y dimensiones ${ }^{19}$.

Lo que, para seguir con los ejemplos anteriormente citados, explica también el hecho de que aún después de más de un milenio de continua y renovada, aunque nunca totalmente lograda "cristianización" ${ }^{20}$, la cultura campesina europea sigue sobreviviendo y reinterpretando a las cosmogonías cristianas desde la perspectiva naturalista, radical, utópica y materialista propia de esas clases subalternas, lo que se retrata de una manera tan clara en el caso del audaz y valeroso Menocchio, del mismo modo en que vemos que los indígenas de Nueva España le rinden culto a efigies de la Virgen María, que sólo recubren un interior en el que se encuentran escondidas las figurillas de las distintas variantes indígenas autóctonas de dichas diosas de la tierra y de la fertilidad, anteriormente mencionadas.

Lo que sin embargo, no debe llevarnos a la falsa e ingenua idea de que, desde esta confrontación, y cada una por su lado, dicha cultura hegemónica, o cada una de esas culturas subalternas son a su vez entidades homogéneas o que funcionan con una sola lógica unívoca e inmodificable. Por el contrario.

Porque dada esta circularidad y confrontación permanentes entre ambos ámbitos culturales, es que cada uno de ellos está constituido también por un complejo abanico de posiciones y elementos que abarcan, desde posiciones que del lado de las clases dominantes, sólo afirman de modo nítido y directo la dominación social, o del lado de las clases subalternas sólo reivindican sin ambages la resistencia radical encaminada a subvertir totalmente esa dominación, hasta muy diversas posiciones que incluyen toda una gama de posturas intermedias posibles en ambos extremos del espectro cultural correspondiente. Y entonces, la cultura de las clases populares contendrá lo mismo elementos de una aculturación hegemónica triunfante, que legitiman y reproducen lisa y llanamente la explotación económica, el despotismo político y la dominación y discriminación sociales, que otras figuras no funcionales a dicho dominio pero igualmente toleradas y subsistentes dentro de este vasto universo cultural, junto a figuras culturales que encarnan muy diversos grados de reinterpretación y de refuncionalización de los mensajes principa- 
les de la cultura hegemónica, desde la óptica y desde las perspectivas de dichas clases y culturas subalternas ${ }^{21}$.

E igualmente del lado de la cultura hegemónica, la que lejos de ser un bloque monolítico y sin fracturas, es también un abanico variado de posturas, en donde domina sin duda aquella que legitima y justifica el orden social existente, pero dentro de la que igualmente pueden aparecer posturas críticas de dicha cultura oficial, que desde el interior, contradecían y ponían en cuestión esa misma hegemonía cultural. Lo que también se hará evidente en el momento en que las posturas de Michel de Montaigne o de Miguel Servet lleguen a coincidir, cada una por su propia vía y muy probablemente sin necesariamente conocerse entre sí, con las propias posturas del molinero Domenico Scandella.

Rompiendo entonces con una concepción muy ampliamente difundida todavía hasta los años setentas, que consideraba tanto a la cultura hegemónica como a las culturas subalternas como construcciones homogéneas y aburridamente univocas y coherentes, Carlo Ginzburg va a deslindarse críticamente tanto de aquellas posturas que a veces idolatran acríticamente a una supuesta cultura popular, concibiéndola como siempre "benigna", positiva, revolucionaria por esencia y exenta de pecado alguno, como también de la noción de una cultura dominante sin fallas, puramente represiva, avasallante, omnipresente y negadora en absoluto de dichas culturas subalternas. Pero también y del mismo modo, de las posturas inversas que, viendo igualmente a las culturas como bloques construidos de un solo material y en una sola colada, consideraban a la cultura popular como mero conjunto de supersticiones y creencias puramente irracionales, de dominio total de la afectividad y de visiones mágicas y simbólicas hoy ya "primitivas", anacrónicas y retrasadas, a la vez que ubicaban a la cultura dominante como la única y verdadera cultura "científica", racional, progresista, creativa, innovadora y "digna” de ser estudiada y examinada sistemáticamente.

Lo que necesariamente nos lleva entonces a la asunción de la diversidad enorme y de la clara heterogeneidad intrínseca tanto de la cultura hegemónica como de las culturas subalternas, heterogeneidad que se proyecta también en el hecho de que su cambiante y complicada interrelación no es entonces una relación rígida, maniquea y de un solo sentido, sino por el contrario una relación móvil y maleable, en la que podemos encontrar lo mismo convergencias culturales indudables, que una cerrada y evidente contraposición radical entre ambas, junto a múltiples situaciones de compromiso y de mutuas concesiones, tanto hacia las clases dominantes como hacia las clases sometidas, dentro de una rica dialéctica de alianzas temporales, retiros y avances recíprocos, conquistas y reconquistas permanentes de parte de ambos bandos, lo 
mismo que giros decisivos y batallas definitivas, que puntúan y determinan de manera central el itinerario global de esta misma dialéctica.

Diversidad y heterogeneidad intrínsecas de cada espacio o ámbito cultural y de sus mutuas relaciones, que de cualquier manera no elimina el hecho de que se trata de una relación asimétrica, jerárquica y siempre desigual, de una relación en la que "los dados están cargados" para asegurar la mayor parte de las veces la victoria a las clases dominantes y hegemónicas en turno. Porque si una cultura es hegemónica lo es en la medida en que expresa las ideas y la Weltanschauung de la clase dominante, las que mediante la imposición y el consenso terminan enseñoreándose como las visiones hegemónicas dentro de una sociedad determinada. Para lo cual disponen, además, de múltiples medios y puntos de apoyo, que van desde el monopolio de la escritura y con ello también el de la fabricación de los testimonios escritos y de los documentos de todo tipo ${ }^{22}$, hasta la construcción misma del lenguaje y de los elementos del discurso, que al ser "teorizados" y "definidos" por dichas clases hegemónicas, van también siendo domesticados y adaptados para nombrar y para expresar del mejor modo posible a ese mismo mundo desigual y asimétrico que los ha creado y que los refuncionaliza permanentemente. Pero también, a partir de que dichas clases hegemónicas poseen siempre los medios materiales tanto para la más vasta difusión y proyección de sus propias ideas y cosmovisiones, como también para la represión y el bloqueo de las distintas formas y figuras de las culturas subalternas.

Porque la cultura de las clases populares ha sido durante siglos y milenios una cultura exclusivamente oral, e incluso aún hoy en día ella sigue siendo predominantemente oral. Lo que implica que al pasar de esta condición dominante suya hacia el terreno de lo escrito, sufra siempre una doble violencia y deformación: en primer lugar la de su reencuadramiento dentro de los términos y conceptos de un lenguaje ya resignificado por la cultura hegemónica, y en segundo lugar la de su inevitable "traducción" por parte de quien escribe, el que en la inmensa mayoría de los casos pertenece también a dichas clases dominantes o hegemónicas. Lo que se hace evidente en el hecho de que los inquisidores no comprendan lo que significa el término de "Benandanti" y terminen forzando su significado hasta terminar equiparándolo con el de "brujo", pero también en el hecho de que a Menocchio le falten los términos y los conceptos necesarios para expresar de modo realmente adecuado su propia cosmovisión campesina y subalterna del mundo ${ }^{23}$.

Aunque, y una vez más de una manera solo aparentemente paradójica, si bien esa cultura hegemónica dispone de todos estos medios para imponerse y enseñorearse sobre las culturas populares, dicho esfuerzo o estrategia de imposición hegemónica se realiza y se reactualiza permanentemente, precisamente por el hecho de que, a pesar de su condición de sometimiento y de su- 
balternidad, la cultura de las clases populares continúa siendo una cultura fuerte en sí misma, con una enorme densidad histórica subyacente, con un cierto grado de autonomía irreductible y con una fuente inagotable de regeneración y renovamiento que le es propia, y que es a fin de cuentas, imposible de expropiar.

Pero todos estos rasgos específicos de las culturas subalternas, sólo es posible percibirlos adecuadamente cuando uno se ubica, como lo propone también Carlo Ginzburg, desde el 'punto de vista de las víctimas', desde la perspectiva y el singular modo de percepción cultural de esas mismas clases sometidas, explotadas, marginadas y discriminadas cuya cultura es justamente el objeto de estudio que nuestro autor se ha planteado rescatar y descifrar.

\title{
Una Historia Cultural CONSTRUida Desde
}

\section{'La Perspectiva de Las Victimas'}

\author{
"Por medio de la introyección (parcial o total, lenta o \\ inmediata, violenta o aparentemente espontánea) del \\ estereotipo hostil propuesto por los perseguidores, las \\ víctimas acababan perdiendo su identidad cultural propia” \\ Carlo Ginzburg, 'Introducción', Historia nocturna, 1989.
}

Un último rasgo fundamental de este modelo de historia cultural construido y ejemplificado por Ginzburg en El queso y los gusanos, y que tal vez sea su rasgo más característico y original, es su insistencia en tratar de reconstruir dichas culturas subalternas no desde una óptica "externa", aunque pueda incluso ser solidaria con los oprimidos, sino más bien desde una perspectiva o visión "interna" a su propio objeto de estudio, que asuma el desafío de preguntarse y de refigurar intelectualmente cómo esas mismas figuras y fenómenos culturales eran vistos, asimilados, y percibidos, pero también proyectados y actualizados por sus propios detentadores, por sus mismos protagonistas, es decir por dichas clases subalternas de la sociedad.

Con lo cual, y una vez más, Carlo Ginzburg va a reproducir un trazo característico de las generaciones de 1968, las que en muy distintas variantes y versiones van también a reclamar la necesidad de 'abolir' o traspasar de alguna manera esa frontera invisible pero poderosa entre el 'nosotros' que somos los investigadores de lo social y los intelectuales con vocación crítica y social, y el 'ellos' que son dichas clases populares. Y entonces se desarrollarán, entre muchas otras expresiones posibles, lo mismo los célebres 'Talleres de historia' (History Workshops) en los que juntos y en colaboración directa participarán 
historiadores de profesión con obreros, campesinos o habitantes de un barrio, que reconstruyen la historia de un sindicato, de una localidad, de una huelga o de un movimiento social determinado, que la experiencia múltiple de profesionistas que, para poder llevar a cabo un trabajo de organización y de penetración política en los sectores populares, renuncian a los privilegios de sus títulos universitarios para trabajar como obreros, campesinos o jornaleros en una fábrica, un taller o una empresa agrícola cualquiera. Y también, y en esta misma vía, los diversos esfuerzos que abarcan los intentos de estudiar a dichas clases subalternas o populares, rescatando su historia, su memoria y su identidad, pero también aquellos destinados a rescatar sus discursos y su propia 'voz', otorgándoles ahora el protagonismo que durante siglos y milenios les fue negado por la historiografía tradicional.

Pero asumiendo que aún estas posturas pueden mantener dicha relación de exterioridad con dichas clases subalternas, al tomar sólo como un 'objeto de estudio' más a dicha cultura de las clases subalternas, o al 'incoporar' sin más a dichas voces y testimonios directos de los oprimidos dentro de los viejos discursos históricos, pero sin asumir el cambio que este nuevo tema y estas nuevas voces implican en términos de renovar igualmente los 'métodos', los paradigmas y los conceptos, el modo de concebir el estatuto de la prueba y las formas del control y la verificación de los resultados historiográficos, las formas de la narración o de la comunicación con el nuevo público, o los vínculos con los posibles nuevos 'comitentes' del trabajo del historiador, entre otros, Carlo Ginzburg va a proponer el claro y mas radical objetivo de penetrar más allá de los testimonios habituales y de los discursos tradicionales, para lograr atrapar el elemento 'dialógico' subyacente en todos esos testimonios y discursos, y a través de este mismo elemento, y de otra serie de procedimientos oblicuos, indirectos, indiciarios y a contrapelo, acceder finalmente y de alguna manera a esa misma cultura de las clases subalternas, pero vista y reconstruida desde su propio punto de vista, desde la posición y la percepción mismas de los perseguidos y de las víctimas.

Cambio entonces fundamental de la perspectiva, que más que interesarse por los perseguidores para condenarlos moralmente, o por los mecanismos de la persecución para explicarlos sólo antropológica o sociológicamente, se interesa también y sobre todo por los propios perseguidos, y por el modo en que ellos han vivido, sufrido, asimilado y procesado dicha persecución, sometimiento, explotación o discriminación, pero también dicha violencia, hegemonía e imposición culturales. Un cambio de óptica que le permitirá a Ginzburg penetrar de una manera mas profunda y mas esencial en varias de las características principales de estas culturas subalternas, algunas de las cuales ya hemos mencionado y señalado antes, y a las que cabe agregar todavía algunas otras. 
En primer lugar, el trazo de la enorme vitalidad y fuerza intrínseca que posee esta cultura de las clases populares, y que deriva del hecho de que dicha cultura, como toda cultura posible, se genera, se reproduce y se renueva siempre a partir del multiforme y complejo proceso de la reproducción social global, que se cumple a través del cotidiano y simple despliegue del vasto conjunto de las actividades humanas en general. Puesto que, si en buena lógica materialista, el mundo de la cultura y de las ideas se ha configurado y ha existido siempre como una de las tantas estrategias humanas posibles para enfrentar y hacer posible la vida de los hombres y de las sociedades dentro de la naturaleza y dentro del planeta, entonces resulta claro que en ese proceso mismo de reproducir su propia vida, y de producir y reproducir con ello a la sociedad entera, las clases trabajadoras y populares, están también constante e inevitablemente produciendo, generando, reproduciendo y renovando nuevas formas y nuevas figuras de su propia cultura y de la cultura en general.

Y dado que dichas clases populares laboriosas, constituyen siempre y hasta hoy la inmensa mayoría de las sociedades, entonces resulta lógico que sean ellas el principal agente productor y generador de la cultura en general. Lo que entonces, nos permite entender la razón de ese fenómeno tantas veces señalado por los estudiosos de la historia y de los temas culturales, de que una gran parte de la llamada 'gran literatura' tenga su origen y su fuente nutricia en la literatura popular anónima y en las leyendas y tradiciones de esas clases subalternas, igual que el teatro clásico ha nacido y sigue alimentándose hasta hoy del teatro popular, y de la misma manera en que la actividad científica se ha visto siempre mas estimulada y acicateada por los problemas prácticos que le plantea la vida, la producción económica, el trabajo o la actividad cotidiana de los hombres, que por cualquier especulación o reflexión puramente teórica o abstracta.

Algo que incluso se proyecta en la propia reflexión histórica y en la historia de la historiografía, la que entre otras de sus fuentes importantes tiene también la de la memoria social y los recuerdos colectivos populares, junto a la necesidad de definir y redefinir constantemente las identidades de las clases sociales, populares y no, mediante el recurso a la crónica, al relato de los sucesos antiguos, a las lecciones del pasado, o a las propias 'enseñanzas de la historia'.

En segundo lugar, las culturas subalternas poseen una densidad intrínseca y una capacidad de renovación inagotable, que deriva también del hecho de que ellas poseen una conexión privilegiada e ineliminable con una parte mayoritaria del mundo de la experiencia práctica. Porque como lo ha señalado muy bien Carlo Ginzburg, las culturas subalternas nacen y se recrean cotidianamente desde y a partir de ese mundo directo de la experiencia, mundo que tanto en el trabajo como en la vida cotidiana es mayoritariamente creado 
y reproducido por esas mismas clases trabajadoras y populares, las que desde su observación atenta y su metabolismo prolongado con dicha experiencia del mundo, van decantando, depurando y acumulando todo ese conjunto de saberes populares campesinos, obreros, artesanos, etc., que transmitido de generación en generación, y siempre por la vía de la tradición oral, posee dicha conexión inmediata y privilegiada con las múltiples formas de manifestación de la actividad práctica ${ }^{24}$.

Saber popular que es el núcleo de dichas culturas subalternas, que no es ni inferior, ni más primitivo o limitado que el "saber erudito" o "el saber del libro", sino simplemente un saber diferente y alternativo a este último. Saber popular que habiendo tenido un rol mucho más central y protagónico durante la milenaria etapa de las sociedades precapitalistas, vendrá en cambio a ser marginado, menospreciado y jerárquicamente relegado por la específica modernidad capitalista de los últimos cinco siglos transcurridos.

Pero a pesar de poseer en un grado mucho menor ese formidable instrumento que es la abstracción, con todas sus implicaciones, este saber popular y esas culturas subalternas a él conectadas, no dejan de ser saberes y culturas que, como resultado de su progresivo refinamiento milenario, poseen también una indudable densidad y capacidad de aprehensión y explicación del mundo, que le ha permitido a la humanidad sobrevivir durante siglos y milenios, mucho antes y más allá de los saberes eruditos, del conocimiento científico y de la existencia misma de muchas de las culturas hegemónicas desplegadas a lo largo de la historia ${ }^{25}$.

Porque como todo saber y cultura, las culturas subalternas son también una mezcla de verdades ciertas e importantes y de conocimientos fragmentarios o erróneos sobre el mundo, combinando, igual que las culturas hegemónicas, elementos racionales y elementos irracionales, verdades probadas y simples conjeturas, supersticiones específicas y elementos de crítica aguda, o afectos emotivos junto a análisis objetivos y acertados sobre la realidad. Y también, y en contra de una opinión ampliamente extendida, esas culturas subalternas no son ni mucho menos inmóviles o "tradicionales" y de muy lenta evolución y cambio, sino por el contrario, culturas que precisamente gracias a su conexión inmediata con la experiencia, son particularmente dúctiles y fluidas, mudando y transformándose todo el tiempo, para enriquecerse y complejizarse al ritmo mismo en que lo hace dicho mundo de la experiencia práctica de las sociedades y de los hombres.

Cultura subalterna que además, y finalmente, posee una autonomía de la que carecen las culturas hegemónicas. Porque del mismo modo en que el capital no puede existir sin el trabajo al que explota, y en que los dominadores no pueden tener existencia más que a partir de que los dominados aceptan de un modo u otro su dominación, de esa misma forma la cultura hegemónica lo es 
sólo y exclusivamente en la medida en que logra imponerse y hegemonizar a dichas culturas subalternas, de las que constantemente se alimenta, y a las que todo el tiempo intenta reencuadrar dentro de sus códigos y significados.

Pero si no hay capital sin trabajo ni dominio sin dominados, el trabajo en cambio puede existir tranquilamente sin el capital, y los antiguos dominados sin el dominio al que antes estuvieron sometidos. Por eso, la cultura de las clases populares podrá también sobrevivir, desarrollarse y expandirse sin problemas cuando todas las culturas hegemónicas y todas las clases dominantes y explotadoras hayan ya desaparecido de la historia y de la faz del planeta. Y entonces, sin duda alguna, esas culturas subalternas dejarán de ser tales y florecerán sin trabas, cuando esa humanidad "redenta, es decir liberada" de la que habla Carlo Ginzburg citando a Walter Benjamin, haya sido capaz de inaugurar una nueva y más feliz etapa de esta historia humana, por la que hoy todavía nos desvelamos, teórica y prácticamente, todos los seguidores genuinamente críticos de esa caprichosa pero extraordinaria e interesantísima Musa Clío.

\section{NOTAS}

${ }^{1}$ Hace dos años, en España, se publicó un libro cuyo argumento general giraba en torno a la pregunta de cuáles eran las razones que explicaban este éxito e impacto extraordinarios de El queso y los gusanos. Se trata del libro de Anaclet Pons y Justo Serna Cómo se escribe la microhistoria, Ed. Cátedra, Valencia, 2000. Curiosamente, aunque el libro construye todo su argumento en torno de esta pregunta, al final termina sin responderla. No obstante se encuentran en este libro muchas informaciones útiles para poder construir, en el futuro, una verdadera historia crítica del proyecto intelectual de la microhistoria italiana, proyecto aún por realizar, y que constituye sin duda, uno de los capítulos centrales de la historia de la historiografía mundial de los últimos treinta años. Sobre los impactos diversos que ha tenido El queso y los gusanos, y que han dado lugar a obras de teatro, documentales, programas de radio y de televisión y hasta a la fundación de un Centro Cultural en Montereale, cfr. el libro recién mencionado Como se escribe la microhistoria, pp. $24-25$.

${ }^{2}$ Aunque resulta curioso observar que, en diversas entrevistas, Carlo Ginzburg insiste siempre en la idea de que, si bien El queso y los gusanos es su obra más conocida y difundida, ello tal vez no implica que sea su mejor libro, duda que al propio Ginzburg le gusta dejar siempre como una interrogante abierta. A título de simples ejemplos, véanse las diversas opiniones incluidas en "Carlo Ginzburg: an Interview" en Radical History Review, num. 35, 1986, "História e Cultura: conversa com Carlo Ginzburg” en Estudos Históricos, vol. 3 , num. 6, 1990 y la Entrevista sólo titulada 'Carlo Ginzburg', incluida en el libro As muitas faces da historia. Nove entrevistas, Ed. UNESP, Sao Paulo, 2001.

${ }^{3}$ Vale la pena llamar la atención de que esta originalidad y universalidad del modelo de his- 
toria cultural contenido en El queso y los gusanos, no ha escapado a la atención de Fernand Braudel, quien al recibir el libro de parte del editor Giulio Einaudi y leerlo, le escribió de inmediato para solicitarle la autorización para una posible traducción en francés, diciéndole: “....acabo de comenzar la lectura del libro de Carlo Ginzburg, que tiene un título que es imposible de traducir al francés, Il formaggio e $i$ vermi, y encuentro que es una obra maestra. Si es posible, quisiera tratar de incluirlo en la colección que dirijo en la Editorial Flammarion. Si usted me da su aprobación, hablaré sobre este tema con mi editor lo más pronto posible". Esta afirmación de Fernand Braudel se encuentra en la carta dirigida a Giulio Einaudi del 16 de febrero de 1976, incluida en el Fólder "Editorial Einaudi" dentro del Dossier "Editeurs" en los Archivos Fernand Braudel que se encuentran concentrados en el Cubículo o Bureau num. 425 de la Maison des Sciences de l'Homme en París.

${ }^{4}$ Sobre esta preocupación de Carlo Ginzburg por situar sus problemas dentro de esta perspectiva vasta de la longue durée, cfr. por mencionar sólo algunos ejemplos, "Saqueos rituales. Premisas para una investigación en curso", incluido como capítulo 9 del libro, Carlo Ginzburg, Tentativas, Ed. Escuela de Historia, Universidad Michoacana, Morelia, de inminente publicación, así como el 'Prefacio’ del mismo. Véase también su entrevista con Adriano Sofri, "Conversación. Adriano Sofri entrevista a Carlo Ginzburg" en la revista Transverso, num. 1, México, 2001. Sobre esta perspectiva de la larga duración, cfr. Fernand Braudel "La historia y las ciencias sociales. La larga duración" en el libro Escritos sobre historia, Ed. Fondo de Cultura Económica, México, 1991 y también Carlos Antonio Aguirre Rojas, Fernand Braudel y las ciencias humanas, Ed. Montesinos, Barcelona, 1996 y Ensayos braudelianos, Ed. Manuel Suárez Editor, Rosario, 2000, en especial el artículo "La larga duración: in illo tempore et nunc". Y es interesante insistir también en que, más allá de ciertas críticas puntuales de Carlo Ginzburg a Fernand Braudel, una buena parte de las obras principales del propio Ginzburg pueden con todo rigor considerarse como muy creativas y logradas ejemplificaciones de esas estructuras de la larga duración histórica que tanto defendió y cultivó el propio Braudel.

${ }^{5}$ Sobre este proyecto de la microhistoria italiana, totalmente diverso y hasta antitético de la microhistoria mexicana de Luis González y González, cfr. Carlo Ginzburg, "Microhistoria: dos o tres cosas que sé de ella" en Manuscrits, num. 12, 1994, Carlos Antonio Aguirre Rojas "Invitación a otra microhistoria: la microhistoria italiana" en Transverso, num. 1, México, 2001, Antimanual del mal historiador, Ed. La Vasija, México, 2002, capítulo 5, y "La storiografia occidentale nel duemila” en Storiografia, num. 4, Roma, 2000, y Anaclet Pons y Justo Serna "El ojo de la aguja: de qué hablamos cuando hablamos de microhistoria" en Ayer, Num. 12, 1993. Igualmente, resulta útil revisar todo el dossier sobre "La microhistoria en la encrucijada", conjunto de artículos incluidos en la revista Prohistoria, num. 3, Rosario, 1999.

${ }^{6}$ Por eso, Ginzburg ha insistido en el hecho de que lo que en un libro tradicional "macrohistórico" de historia hubiese sido una simple nota de pie de página, en su perspectiva se 
ha convertido en todo un libro completo. Metáfora que es útil para entender en parte lo que es ese procedimiento microhistórico. Sobre las implicaciones de este procedimiento microhistórico, cfr. Carlo Ginzburg y Carlo Poni, "El nombre y el como: intercambio desigual y mercado historiográfico”, incluido como capítulo 2 del libro, Carlo Ginzburg, Tentativas, citado, y de Carlo Ginzburg, "Acerca de la historia local y de la microhistoria" incluido como capítulo 8 del mismo libro Tentativas, recién mencionado. También el ensayo de Carlos Antonio Aguirre Rojas "Invitación a otra microhistoria: la microhistoria italiana”, citado en la nota anterior.

${ }^{7}$ Sobre esta indefinida y poco rigurosa historia de las mentalidades, que distintos historiadores críticos calificaron de "historia paraguas", "historia atrapalotodo", o "cajón de Sastre", y que efectivamente llegó a confundirse lo mismo con la historia del arte o con la historia de la vida cotidiana, que con la psicología histórica, la antropología histórica o la historia de las costumbres, entre muchas otras, resulta instructivo comparar algunos de sus textos más representativos, o que intentan definirla y acotarla de manera más específica. Véase por ejemplo Jacques Le Goff, "Las mentalidades. Una historia ambigua”, en el libro Hacer la historia, Vol. 3, Ed. Laia, Barcelona, 1980, Robert Mandrou, "L'histoire des mentalites", en la Encyclopaedia Universalis, Vol. 8, París, 1961, Georges Duby, "L'histoire des mentalites", en L'histoire et ses methodes, Ed. La Pleyade, París, 1961, Philippe Aries, "La historia de las mentalidades", en el libro La nueva historia, Ed. Mensajero, Bilbao, 1988, o Michel Vovelle, Ideologies et Mentalites, Ed. Gallimard, París, 1982. Comparando sólo estos cinco textos, resulta evidente que no existe ni siquiera una definición única y rigurosa de mentalidades, sino varias, múltiples y diversas, que lo mismo incluyen o excluyen, según los casos, a las "prácticas" cotidianas que al 'inconsciente colectivo', a la emotividad y los sentimientos humanos, que al imaginario simbólico, etc.. Del vasto universo de críticas a esta historia de las mentalidades mencionaremos, a título de simples ejemplos, Georges Lloyd, Las mentalidades y su desenmascaramiento, Ed. Siglo XXI, Madrid, 1996, Francois Dosse, La historia en migajas, Ed. Alfons el Magnanim, Valencia, 1998, Fernand Braudel, "A manera de conclusión” en la revista Cuadernos Políticos, num. 48, México, 1986 y Carlos Antonio Aguirre Rojas “¿Qué es la historia de las mentalidades?. Auge y declinación de un tema historiográfico" incluida en el libro Itinerarios de la historiografía del siglo XX, Ed. Centro Juan Marinello, La Habana, 1999 y también La escuela de los Annales. Ayer, hoy mañana, Ed. Universidad Juárez Autónoma de Tabasco, Villahermosa, 2002.

${ }^{8}$ Es importante señalar que una obra tan importante y tan innovadora como la de Norbert Elías, La sociedad cortesana, ha sido leída bajo esta clave de lectura, intentando utilizar el ejemplo de esa cultura cortesana creada primero en las Cortes europeas y luego difundida a todo el tejido social, que Elías analiza, como prueba de dicho modelo "descendente" del funcionamiento cultural. En nuestra opinión se trata de una lectura errónea, puesto que a Elías lo que le interesa en esta obra es solamente ilustrar las modificaciones esenciales en cuanto a los patrones del comportamiento afectivo y emotivo, y en cuanto a la domestica- 
ción de los instintos y de la "economía psíquica" de los individuos, más que proponer un modelo general del funcionamiento de la cultura europea en su totalidad. Y en este esfuerzo de la pacificación de los instintos guerreros de la clase caballeresca, y de los impulsos de violencia de la sociedad en general, y de la modulación de las conductas y de las relaciones interpersonales, si es claro que se trata de una iniciativa de las clases burguesas europeas proyectada después como un 'modelo a imponer a las clases populares' y a toda la sociedad, como parte del proyecto de afirmación de la nueva sociedad burguesa entonces en vías de consolidación. Sobre estos puntos, cfr. Norbert Elías, La sociedad cortesana, Ed. Fondo de Cultura Económica, México, 1982, y también El proceso de la civilización, Ed. Fondo de Cultura Económica, México, 1989. Puede verse también nuestro ensayo, Carlos Antonio Aguirre Rojas “Norbert Elías, historiador y crítico de la modernidad”, en el libro coordinado por Patricia Nettel, Aproximaciones a la modernidad. París-Berlín siglos XIX y XX, Ed. Universidad Autónoma Metropolitana-Xochimilco, México, 1997.

${ }^{9}$ Resulta obvio que Carlo Ginzburg ha llegado al descubrimiento y a la teorización del célebre paradigma indiciario, precisamente a raíz de este esfuerzo por descubrir las vías que le permitan acceder a esa reconstrucción de las culturas subalternas, vistas además desde el propio "punto de vista de las víctimas" como veremos mas adelante. Sobre estos modos oblicuos e indirectos de acceso a dicha cultura, y sobre las implicaciones que ellos tienen respecto del modo de tratamiento de las 'fuentes' y de los 'testimonios' cfr. del mismo Ginzburg "Huellas. Raíces de un paradigma indiciario", "Intervención sobre el 'paradigma indiciario"”, "De todos los regalos que le traigo al Kaisare... Interpretar la película, escribir la historia", y "El inquisidor como antropólogo", incluidos como capítulos 3, 4, 6 y 10 del libro, Carlo Ginzburg, Tentativas, ya antes referido.

${ }^{10}$ Sobre esta especial riqueza heurística de dichos casos atípicos, pero también sobre las dificultades que ellos conllevan para la reconstrucción histórica, ha llamado la atención el mismo Carlo Ginzburg, en "Pruebas y posibilidades. Comentario al margen del libro El regreso de Martín Guerre de Natalie Zemon Davis" y en "El inquisidor como antropólogo", incluidos como capítulos 7 y 10 respectivamente, del libro, Carlo Ginzburg, Tentativas, ya referido.

${ }^{1}$ Sólo a título de ejemplos, además de las Entrevistas mencionadas en la nota num. 2, pueden verse también la referencias a este punto en el "Prefacio" de El queso y los gusanos, Ed. Océano, México, 1998, el "Prefacio" al libro Mitos, emblemas, indicios, Ed. Gedisa, Barcelona, 1994, y también la "Introducción” al libro Historia nocturna, Ed. Muchnik Editores, Barcelona, 1991. El libro de Marc Bloch, está editado en español, Los reyes taumaturgos, Ed. Fondo de Cultura Económica, México, 1988. El alto grado de conocimiento y de dominio que Carlo Ginzburg tiene de la obra de Marc Bloch — que es una de sus influencias intelectuales fundamentales_, puede verse en su ensayo "A propósito della raccolta dei saggi storici di Marc Bloch" en Studi Medievali, Serie tercera, año VI, fascículo 1, 1965, y en el Prólogo que redactó a la edición italiana de este mismo libro de Los Reyes Taumatur- 
gos, "Prólogo a la edición italiana de I Re Taumaturghi de Marc Bloch" en Argumentos, num. 26, México, 1997.

${ }^{12} \mathrm{Cfr}$. Mijail Bajtin, La cultura popular en la Edad Media y en el Renacimiento. El contexto de Francois Rabelais, Ed. Alianza Editorial, Madrid, 1987.

${ }^{13}$ Sobre esta inversión del mundo y sobre sus raíces dentro de la literatura antigua, cfr. también el ensayo de Mijail Bajtin, "Forms on time and of the Chronotope in the novel" en el libro The dialogic imagination, Ed. University of Texas Press, Austin, 2000.

${ }^{14} \mathrm{Y}$ resultaría interesante explorar la hipótesis de que, en una escala menor, este fenómeno del largo siglo XVI estudiado por Bajtin, tal vez se repite siempre que ha habido una revolución social en cualquier parte del mundo, durante los cinco siglos de existencia de la modernidad capitalista. Porque es claro que, por ejemplo en México, la Revolución Mexicana de 1910-1921, provoca también una clara "invasión” de la cultura popular dentro de la esfera cultural global de México, que llena toda la coyuntura histórica de 1921-1945. Ya que resulta lógico pensar que en este tipo de situaciones, caracterizadas por una suerte de "vacío de poder" dentro de la esfera cultural, cuando la vieja cultura agonizante ha perdido la fuerza para afirmar su dominación y vigencia, y cuando la nueva cultura que ha de dominar en el futuro no ha terminado aún de consolidarse, se abre un espacio que, de manera inmediata y espontánea es ocupado, justamente, por esta siempre viva y activa cultura popular, la que en cuanto encuentra una coyuntura favorable, vuelve a hacerse presente de una manera expansiva y generalizada dentro del ámbito global de esta misma realidad cultural.

${ }^{15}$ Carlo Ginzburg se refiere en especial a los trabajos sobre la 'cencerrada' de Natalie Zemon Davis, incluidos en su libro Sociedad y cultura en la Francia moderna, Ed. Crítica, Barcelona, 1993, y también al ensayo de Edward P. Thompson "La cencerrada inglesa" incluido en el libro Historia social y Antropología, Ed. Instituto Mora, México, 1994, pero igualmente, como es obvio, a su libro La formación de la clase obrera en Inglaterra, 2 volúmenes, Barcelona, 1989. Sobre este mismo tema de la 'cencerrada', cfr. el artículo de Carlo Ginzburg "Charivari, Associazione Giovanile e Caccia Selvaggia” en Quaderni storici, Num. 49, abril de 1982. Una clara y explícita recuperación del fundamental concepto thompsoniano de la 'economía moral de la multitud' se encuentra en el ensayo "Saqueos rituales. Premisas para una investigación en curso" incluido como capítulo 9 del libro, Carlo Ginzburg, Tentativas, antes citado.

${ }^{16}$ Justamente, una parte importante de este conjunto de ensayos es la que se encuentra reunida en el libro, Carlo Ginzburg, Tentativas, que como hemos dicho es de inminente publicación por parte de la Escuela de Historia de la Universidad Michoacana. Sobre el trayecto intelectual mencionado de Ginzburg, resulta interesante comprobar como en el libro de I benandanti, a la vez que se usan todavía los términos de "mentalidad campesina" o "mentalidad en sentido amplio", se critica ya radicalmente a esos "términos vagos y gené- 
ricos como los de 'mentalidad' o 'psicología colectiva”, criticando los estudios de "historia de las 'mentalidades colectivas"” que son sólo "sucesión de tendencias abstractas y desencarnadas". Al mismo tiempo, la relación entre cultura dominante y cultura popular aparece ya como núcleo central del argumento, tanto en su contraposición, como también en el movimiento final de la obligada subsunción de la cultura popular dentro de los esquemas de la cultura dominante. (Cfr. Carlo Ginzburg, I Benandanti, Ed. Giulio Einaudi Editore, Turín, 1997 ( $10^{a}$ reedición, aunque la edición original es de 1966), en especial pp. VII-XV, 125-131, y 156-157. Véase también el capítulo "Folklore, magia, religión" en el libro Storia d'Italia, I caratteri originali, Vol. 2, Ed. Giulio Einaudi, Turín, 1989, aunque la edición original es de 1972). Por otro lado, es claro que la construcción de este modelo de historia crítica de la cultura de las clases subalternas, ya delineado en sus contornos generales en El queso y los gusanos, se seguirá afinando y complejizando hasta culminar su versión más sofisticada y comprehensiva con el libro de Historia nocturna (cfr. Historia nocturna, cit.). En cambio, después de 1989, Carlo Ginzburg ha abandonado un poco la línea hasta entonces seguida para esta construcción de dicho modelo, para adentrarse en una línea de investigación que en parte es nueva y en parte prolonga y profundiza aún más, en una dimensión diferente, dicha construcción de su modelo de historia cultural: la línea del estudio de varios de los supuestos mismos de toda construcción cultural posible, es decir tanto de los mecanismos más generales que determinan la construcción de una cultura (tales como la representación, la formación de los mitos, la creación de arquetipos culturales específicos, o los elementos que del modo más primario y elemental determinan nuestras actitudes culturales más básicas) como también de los mecanismos generales que regulan y moldean el complejo diálogo, intercambio y conflicto entre culturas diversas. Sobre esta última línea de investigación cfr. Ojazos de madera, Ed. Península, Barcelona, 2000, Rapporti di forza. Storia, retorica, prova, Ed. Feltrinelli, Milan, 2000, No Island is an Island, Ed. Columbia University Press, Nueva York, 2000.

${ }^{17}$ Algo que para Carlo Ginzburg es muy claro, como se ilustra muy bien en su "Introduzione" a la edición italiana del libro de Peter Burke, Cultura popolare dell'Europa moderna, Milán, 1980.

${ }^{18}$ Sobre este punto del nacimiento de una verdadera historia social cfr. Carlos Antonio Aguirre Rojas Antimanual del mal historiador, cit. capítulo 3, y también el artículo "Repensando las ciencias sociales actuales: el caso de los discursos históricos en la historia de la modernidad", en el libro Itinerarios de la historiografía del siglo $X X$, antes citado.

${ }^{19}$ Uno de los puntos centrales que Carlo Ginzburg afinará después de 1976, dentro de este modelo de historia cultural que estamos aquí considerando, es este punto de los respectivos "filtros" que, tanto las clases dominantes como las clases populares van a utilizar y a poner en acción al momento de recibir y de asimilar los mensajes provenientes de la cultura opuesta o adversaria, afinamiento que se apoyará muy centralmente en el esquema de Sigmund Freud de la construcción de los sueños, y del paso del nivel del inconsciente al 
nivel de la conciencia, como puede verse claramente en la "Introducción" al libro Historia nocturna citado anteriormente. En este mismo sentido, es interesante ver el artículo del mismo Carlo Ginzburg, "El palomar ha abierto los ojos: conspiración popular en la Italia del siglo XVII", incluido como capítulo 1 del libro, Carlo Ginzburg, Tentativas, antes citado. Sin embargo, de aquí a la ridícula postura sostenida por algunos lectores e intérpretes de Carlo Ginzburg, de que la influencia central más determinante de la obra de Ginzburg es este aporte de Freud, media un enorme abismo que consideramos absurdo tratar de franquear. También, vale la pena señalar que otra de las líneas centrales que serán afinadas y desarrolladas después de 1976 es la del entrecruzamiento, para la explicación de los fenómenos culturales, de la perspectiva 'histórica' con la perspectiva 'morfológica', que aparece también en el ensayo "Datación absoluta y datación relativa: sobre el método de Longhi", incluido como capítulo 5 del libro, Carlo Ginzburg, Tentativas, recién referido.

${ }^{20} \mathrm{Como}$ lo demuestra brillantemente Carlo Ginzburg, en su texto "Folklore, magia, religión", incluido en el libro Storia d'Italia, antes citado.

${ }^{21}$ Sobre este abanico diverso, cfr. la "Premessa Giustificativa" redactada por Carlo Ginzburg como introducción al número sobre el tema de 'La religión de las clases populares', número que fue organizado y coordinado por el mismo Ginzburg y publicado en la revista Quaderni storici, num. 41, mayo-agosto de 1979, pp. 393-397, y también la invitación a la cola100 boración para participar en este número, que había aparecido en las "Páginas Azules" de la misma revista Quaderni storici, num. 37, de enero-abril de 1978, bajo el título "Progetto di un fascicolo sulla 'Religione Popolare'”, pp. 430-431, y que probablemente fue también redactado por el mismo Carlo Ginzburg.

${ }^{22}$ Algo sobre lo que Carlo Ginzburg insiste en su "Intervención sobre el paradigma indiciario", incluido como capítulo 4 del libro, Carlo Ginzburg, Tentativas, tantas veces citado. Mas adelante, Ginzburg insistirá también en el hecho de que cada documento nos remite, para su interpretación adecuada, a la 'red de referencias culturales' del contexto de cada autor, como lo explica en su artículo "Conversar con Orion" incluido como capítulo 11 del mismo libro, Carlo Ginzburg, Tentativas, citado.

${ }^{23}$ Sobre esta 'distancia cultural' entre la cultura oral y la cultura escrita, y sobre la crítica de la falsa jerarquía que tradicionalmente se asume para privilegiar a la segunda y menospreciar a la primera ha insistido Carlo Ginzburg en su Entrevista con Adriano Sofri, "Conversación. Adriano Sofri entrevista a Carlo Ginzburg” en la revista Transverso, antes citada, y en donde incluso defiende y reivindica no sólo a esa cultura oral, sino también a la 'cultura del silencio', $\tan$ importante como las dos anteriores. Algo que resulta muy interesante de conectar con la reciente postura de los dignos indígenas rebeldes neozapatistas mexicanos, que conocen y saben utilizar muy bien esta misma 'cultura del silencio'. Sobre dicha distancia, véase también los libros de I Benandanti, citado, y El queso y los gusanos, también antes mencionado. 
El Queso y los Gusanos: un modelo de Historia critica para el analisis de las culturas subalternas

${ }^{24}$ Sobre esta dimensión de las culturas subalternas como saber popular vinculado a la experiencia cfr. Carlo Ginzburg, "Huellas. Raíces de un paradigma indiciario”, incluido como capítulo 3 del libro, Carlo Ginzburg, Tentativas, antes referido, y también el libro de Bolívar Echeverría, Definición de la cultura, Ed. Itaca, México, 2001.

${ }^{25}$ Sobre este punto quizá valdría la pena adentrarse en la obra de Ernesto de Martino, que Carlo Ginzburg comenta en su ensayo "Momigliano e De Martino" en Rivista Storica Italiana, año 100, fascículo II, Nápoles, 1988.

Artigo recebido em 10/2002. Aprovado em 4/2003. 